\title{
Rubella seroprevalence among women aged 15-39 years in Morocco
}

\author{
H. Caidi, ${ }^{1,4}$ S. Bloom, ${ }^{2}$ M. Azilmaat, ${ }^{3}$ A. Benjouad, ${ }^{4}$ S. Reef ${ }^{2}$ and R. El Aouad ${ }^{1}$
}

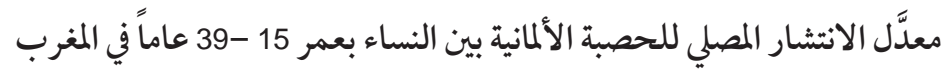

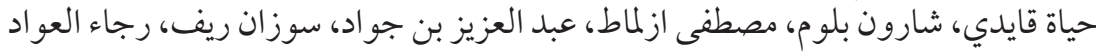

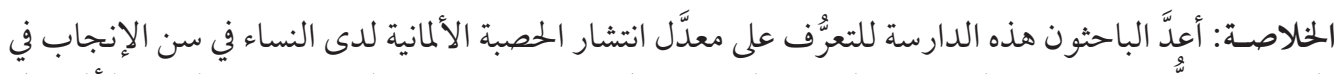

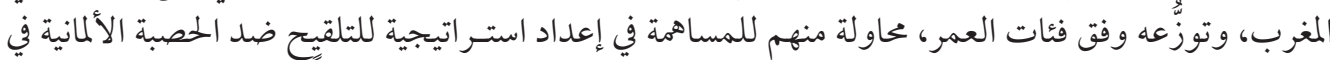

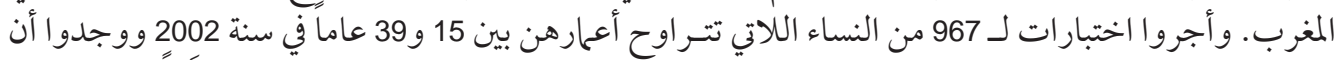

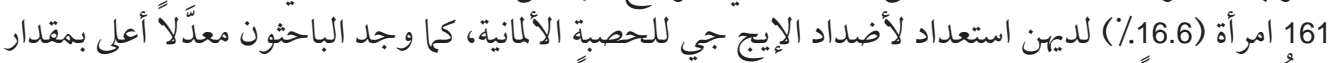

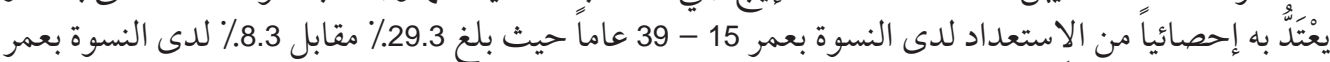

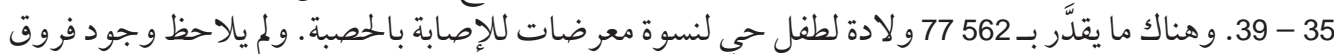

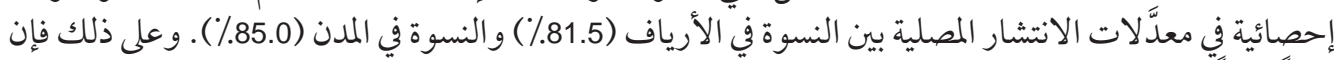

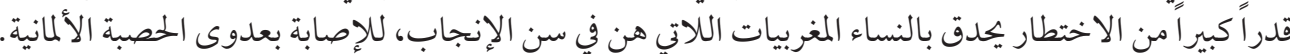

ABSTRACT This study was designed to determine the age-specific rubella seroprevalence in women of childbearing age in Morocco and to contribute to the development of a rubella vaccination strategy in the country. Of 967 women aged 15-39 years tested in 2000, 161 (16.6\%) were susceptible to rubella based on absence of IgG antibodies. A significantly higher rate of susceptibility among women aged $15-19$ years was observed (29.3\%) compared with age 35-39 years (8.3\%). An estimated 77562 live births occur annually to rubella-susceptible women. No statistical difference in seroprevalence was seen between women in rural and urban areas (81.5\% and $85.0 \%$ respectively). A substantial risk of rubella infection exists for Moroccan women of childbearing age.

\section{Séroprévalence de la rubéole chez les femmes âgées de 15 à 39 ans au Maroc}

RÉSUMÉ Cette étude visait à déterminer la séroprévalence de la rubéole par âge chez les femmes en âge de procréer au Maroc, et à contribuer à l'élaboration d'une stratégie de vaccination antirubéoleuse dans le pays. Sur 967 femmes âgées de 15 à 39 ans soumises à des tests en 2002, 161 (16,6 \%) étaient sensibles à la rubéole du fait de l'absence d'anticorps IgG anti-rubéole. Le taux de sensibilité observé chez les femmes âgées de 15 à 19 ans (29,3\%) était significativement plus élevé que chez les femmes âgées de 35 à 39 ans (8,3\%). On estime à 77562 le nombre annuel de naissances vivantes chez les femmes sensibles à la rubéole. En ce qui concerne la séroprévalence, aucune différence statistique n'a été observée entre les femmes vivant dans les zones rurales et dans les zones urbaines $(81,5 \%$ et $85,0 \%$ respectivement). II existe un risque important d'infection par la rubéole chez les femmes marocaines en âge de procréer.

\footnotetext{
${ }^{1}$ National Institute of Hygiene, Rabat, Morocco (Correspondence to H. Caidi: hcaidi@lycos.com). ${ }^{2}$ National Immunization Program, Centers for Disease Control and Prevention, Atlanta, Georgia, United States of America.

${ }^{3}$ Ministry of Health, Rabat, Morocco.

${ }^{4}$ Department of Biology, Mohamed V University, Rabat, Morocco.

Received: 19/09/06; accepted: 20/12/06
} 


\section{Introduction}

Rubella is a mild illness in adults and children and up to $50 \%$ of cases are asymptomatic. However, if a woman is infected during her pregnancy, particularly in the first trimester of pregnancy, serious consequences, such as miscarriage, fetal death/stillbirth or a combination of debilitating birth defects known as congenital rubella syndrome (CRS), may occur [1]. The clinical manifestations of CRS include hearing impairment, heart defects, ocular abnormalities and mental retardation. Worldwide, it is estimated that over 100000 infants are born with CRS annually [2].

The main goal of rubella vaccination programmes is to eliminate or reduce rubella infection in pregnant women and the concomitant risk of CRS in their babies [3]. A country's decision to begin infant or childhood rubella vaccination often relates to the level of its measles control and planned enhanced measles control activities [4]. In the World Health Organization (WHO) meeting on CRS in 2000, one of the recommendations was that countries undertaking measles elimination should consider rubella elimination by using measles and rubella (MR) vaccine through the childhood programme of vaccination. In addition, countries should ensure immunity among women of childbearing age $[5,6]$.

In 2003, Morocco introduced MR vaccine into the routine childhood immunization programme. Children were to receive MR vaccine at school entry (age 6 years). Routine measles coverage in Morocco was estimated at $94 \%$ in 2005 [7]. Estimated MR vaccination coverage is greater than 90\%. While Morocco does not collect rubella and CRS surveillance data, seroprevalence studies in Moroccan women of childbearing age undertaken between 1970 and 1999 showed that $14.8 \%$ to $33.5 \%$ were seronegative $[8,9]$. A retrospective chart review performed by one of the authors esti- mated an average annual CRS rate of 8.5 per 10000 live births between 1990 and 2000 [10]. Measles, mumps and rubella (MMR) vaccine has been increasingly used in the private health care sector in Moroccan cities since 1987 , but up to 2002 , nationwide only about $5 \%$ of the birth cohort was vaccinated against rubella (Aventis-Pasteur, written communication, 2003).

To provide the Moroccan Ministry of Health with a more up-to-date profile of rubella risk among women of childbearing age, we performed a serological study in 2003 on an existing collection of sera from a nationally representative serosurvey of anaemia in the year 2000 .

\section{Method}

\section{Sample}

Sera were used from a Ministry of Health project sponsored by the United Nations Children's Fund (UNICEF) that was conducted in the year 2000 with the primary goal of estimating the prevalence and risk factors for iron-deficiency anaemia and goitre among women of reproductive age. The sample of women in the UNICEF-sponsored study used the same sampling scheme as the 1997 national survey of mother and child health (PAPCHILD) [11]. In the original 2000 study, 1524 women of childbearing age (15-45 years) were enrolled. From these women, $967(63.5 \%)$ sera were available for testing of rubella-specific immunoglobulin $\mathrm{G}(\mathrm{Ig} G)$.

\section{Data collection}

All testing was conducted at the national laboratory in Rabat, Morocco. An IgG enzyme-linked immunoassay was used to detect rubella-specific IgG antibodies, according to the manufacturer's specifications [Wampole Laboratories, Cranbury, New Jersey, United States of America (USA)]. For quality assurance, $10 \%$ of the negative

المجلة الصحية لشرق المتوسط، منظمة الصحة العالمية، المجلد الخنامس عشر، العدد ب، 9 +. 
and positive sera were retested at the MMR laboratory of the Centers for Disease Control and Prevention (CDC) in Atlanta, USA. The 10\% positive and negative sera retested at CDC were consistent with results in Morocco. The limit of detection of the test is 6.2 $\mathrm{IU} / \mathrm{mL}$. Individuals with an $\mathrm{IgG}$ titre $>8.6$ $\mathrm{IU} / \mathrm{mL}$ were defined as seropositive. Titres of $6.2-8.6 \mathrm{IU} / \mathrm{mL}$ were classified as borderline. In this analysis, women with borderline or negative test results were considered as susceptible, which yielded a maximum estimate of rubella susceptibility for the purpose of developing a vaccination strategy.

\section{Analysis}

Five-year age strata (15-19, 20-24, 25-29, 30-34 and 35-39 years) were used to describe susceptibility levels. Data were analysed using Epi-info, version 6. The Pearson chi-squared test was used to examine the association between susceptibility and age.

We estimated the number of CRS cases by fitting various catalytic models to the seroprevalence data via the method of maximum likelihood. Using the age-specific force of infection from this model, together with demographic data such as the population of women by age, we calculated the number of women infected with rubella per year. Using data on birth distribution by age of mother, we determined the annual number of women infected while pregnant. Adjusting for risks specific to the gestation period, we estimated the number of CRS cases per year.

\section{Results}

Of the 967 women aged 15-39 years, 161 (16.6\%) had negative or borderline test results (Table 1). The difference in susceptibility between the oldest (35-39 years) and youngest age group (15-19 years) was statistically significant: $12 / 145(8.3 \%)$ versus
51/174 (29.3\%) $(P<0.0001)$. Comparing women of childbearing age by geographic location (urban versus rural), no statistical difference in the seroprevalence rate was seen between women in rural and urban areas (total $81.5 \%$ and $85.0 \%$ respectively), in any of the age groups (Table 1).

A review of the national statistics on birth distributions by maternal age for the year 2003 revealed that $9.1 \%$ of all births in Morocco occurred among women aged 15-19 years, $23.8 \%$ among ages 20-24 years, 25.7\% among ages 25-29 years, $21.9 \%$ among ages $30-35$ years and $14.0 \%$ among ages $35+$ years (Table 2). Applying this distribution of births to the proportion of susceptible women in each age group, we estimated the susceptible births by the age of the mother. An estimated total 21154 births occurred annually to rubella-susceptible women aged 25-29 years, and 77562 to all women of childbearing age.

The annual number of births in Morocco is approximately 338879 [7]. According to $\mathrm{CDC}$ estimates for the number of CRS cases in Morocco (Glasser RI, personal communication), we estimated that around 916 children are born with CRS each year, 555 in urban and 361 in rural areas.

\section{Discussion}

This study provides the first national level data on the rubella seroprevalence and will serve as a baseline now that MR vaccine has been introduced into the population. The high proportion of women of childbearing age susceptible to rubella $(16.6 \%)$ indicates a high risk of CRS in Morocco. In addition to susceptibility data, we used all available data evidence, such as the distribution of births by maternal age, the high proportion of women of childbearing age and also the early age at marriage in rural and urban areas in an attempt to develop 
an optimal rubella vaccination strategy in Morocco. In fact, $71.3 \%$ of all births occurred among women aged 20-34 years, the age group most susceptible to rubella exposure.

Studies conducted in many countries have shown a different seroprevalence of rubella antibodies among women of childbearing age; for example, $96.2 \%$ in Shiraz, Islamic Republic of Iran [12] and $90.1 \%$ in Senegal [13]. Achieving elimination of rubella and CRS requires vaccination coverage of children and women of childbearing age [14]. Moreover, different levels of susceptibility do not necessarily predict the same risk of CRS, because of the variation in the force of infection, population density, migration and birth patterns and other factors $[3,15,16]$. Likewise, there is $19 \%$ consanguinity in Morocco [17], and consanguinity has been shown to be associated with an increased risk of birth defects, some of which resemble CRS [18]. In addition, comparison of susceptibility levels is difficult due to different designs and timing of studies in relation to previous outbreaks, variability of testing and titre cut-off points used to define susceptibility.

In Morocco, several barriers remain to achieving rubella vaccination coverage in persons of childbearing age. A major barrier is limited access to preventive health care by rubella-susceptible populations. Because rubella vaccination is not mandated and universally provided for adults, more complex, targeted strategies are needed to ensure that adults of childbearing age are rubella immune. In addition, before 2003 rubella vaccine was available only in the private health sector, so childhood immunization coverage remains low, and transmission patterns of rubella infection may shift towards adults, including women of childbearing age $[19,20]$. Although, in general, the presence of specific antibodies correlates with protection, there are differences between tests in the cut-off level at which results are reported as "positive". Even when the same cut-off is used, differences between commercial kits exist, which reflect different antigen preparations and test parameters used. It is known that reinfection can occur in individuals with pre-existing antibody levels above the accepted cut-off level and is more common after 


\begin{tabular}{|c|c|c|c|c|}
\hline \multirow[t]{2}{*}{$\begin{array}{l}\text { Age group } \\
\text { (years) }\end{array}$} & \multicolumn{2}{|c|}{$\begin{array}{l}\text { Annual live births in } \\
2002^{\mathrm{a}}(n=528553)\end{array}$} & \multirow[t]{2}{*}{$\begin{array}{l}\% \text { of women } \\
\text { susceptible }^{b}\end{array}$} & \multirow{2}{*}{$\begin{array}{l}\text { Estimated no. } \\
\text { of susceptible } \\
\text { pregnant women }\end{array}$} \\
\hline & No. & $\%$ & & \\
\hline$\overline{15-19}$ & 48014 & 9.1 & 29.3 & 14068 \\
\hline $20-24$ & 125793 & 23.8 & 17.8 & 22391 \\
\hline $25-29$ & 135602 & 25.6 & 15.6 & 21154 \\
\hline $30-34$ & 115808 & 21.9 & 11.9 & 13781 \\
\hline 35-39 & 74313 & 14.0 & 8.3 & 6168 \\
\hline
\end{tabular}

Source: United Nations demographic yearbook

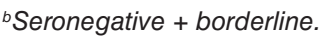

immunization than after natural infection $[18,21]$. Antibody levels greater than $15 \mathrm{IU} /$ $\mathrm{mL}$ are usually considered to be protective against reinfection [22].

Our findings highlight the need for the country to establish surveillance of trends in susceptibility to rubella and CRS incidence and perhaps to introduce of rubella vaccination among women of childbearing age. Overall, in Morocco, MMR vaccination in the private health sector is likely to lead to long-term increases in the burden of CRS among women. who do not have access to the private sector [23]. Eliminating rubella and CRS in Morocco will not occur until national rubella vaccination programmes are expanded to include vaccination coverage for children and women of childbearing age. As the first national level data on seroprevalence of rubella among women of childbearing age, our results will be useful for future studies in this domain.

\section{Acknowledgements}

The authors would like to thank Dr Joseph Icenogle and Mrs Emily Abernathy, Centers for Diseases Control and Prevention, Atlanta, Georgia, and Dr Imad Cherkaoui, Ministry of Health, National Institute of Hygiene, Rabat, Morocco.

\section{References}

1. Roberston SE et al. Control of rubella and congenital rubella syndrome (CRS) in developing countries. Part 2: Vaccination against rubella. Bulletin of the World Health Organization, 1997, 75:69-80.

2. De Nobrega M, Maurice WLL, Juliano Y. Study of the hearing loss in children and adolescents, comparing the periods of 1990-1994 and 1994-2000. International journal of pediatric otorhinolaryngology, 2005, 69:829-38.

3. Jazbec A, Delimar M, Vrzic VS. Simulation model of rubella, the effects of vac- cination strategies. Applied mathematics and computation, 2004, 153:75-96.

4. Centers for Diseases Control. Measles, mumps, and rubella-vaccine use and strategies for elimination of measles, rubella, and congenital rubella syndrome and control of mumps: recommendations of the Advisory Committee on Immunization Practices (ACIP). Morbidity and mortality weekly report, 1998, 47(RR8): $1-57$.

5. Control of rubella and congenital rubella syndrome (CRS) in developing countries. 
Geneva, World Health Organization, 2001 (WHO/V\&B/00.03)

6. Kanbur NO et al. Age specific rubella seroprevalence of an unvaccinated population of adolescents in Ankara, Turkey. Japanese journal of infectious disease, 2003, 56:23-5.

7. Santé en chiffre 2005. Edition 2006. Rabat, Ministry of Health, 2005 (http://www. sante.gov.ma/Departements/dprf/SEIS/ SanteEnChiffres.htm, accessed 27 January 2008).

8. Nejmi S, Nazih A, Omri B. Enquête immunologue sur la rubéole chez la femme Marocaine de la région de Rabat [Immunological survey of rubella in women of the Moroccan region of Rabat]. Maroc médicale, 1972, 52:420-5.

9. Nejmi S, L'Kassmi H. Profil immunitaire de la femme Marocaine vis-à-vis de la rubéole et de la toxoplasmose. Enquête immunologique sur la rubéole chez la femme Marocaine de la région de Rabat et de Meknès [Immune profile of Moroccan women vis-à-vis rubella and toxoplasmosis. Immunological survey of rubella in women of the Moroccan region of Rabat and Meknes]. Paper presented at the Fifth National Congress of Neonatology, Meknès, Morocco, 2003.

10. Bloom S et al. Congenital rubella syndrome burden in Morocco: a rapid retrospective assessment. Lancet, 2005, 365:135-41.

11. Azelmat M. 1997 National survey on mother and child health (PAPCHILD). Rabat, Ministry of Health, and Cairo, Arab League, 1999.

12. Doroudchi M et al. Seroepidemiological survey of rubella immunity among three populations in Shiraz, Islamic Republic of Iran. Eastern Mediterranean health journal, 2001, 7(1/2):128-38.

13. Dromigny JA, Nabeth $P$, Perrier Gros Claude JD. Evaluation of the seroprevalence of rubella in the region of Dakar
(Senegal). Tropical medicine and international health, 2003, 8(8):740-3.

14. Dykewicz CA et al. Rubella seropositivity in the United States, 1988-1994. Clinical infectious diseases, 2001, 33:1279-86.

15. Cutts FT, Vynnycky E. Modelling the incidence of congenital rubella syndrome in developing countries. International journal of epidemiology, 1996, 28:1176-84.

16. Cutts FT et al. Control of rubella and congenital rubella syndrome (CRS) in developing countries. Part 1: Burden of disease from CRS. Bulletin of the World Health Organization, 1997, 75:55-68.

17. Bouazzaoui L. Consanguinité et santé publique au Maroc [Consanguineous marriages and public health in Morocco]. Bulletin de l'Académie nationale de médecine, 1994, 178:1013-27.

18. Durkin MS et al. Prenatal and postnatal risk factors for mental retardation among children in Bangladesh. American journal of epidemiology, 2000, 152:1024-33.

19. Hinman AR et al. Economic analyses of rubella and rubella vaccine: a global review. Bulletin of the World Health Organization, 2002, 80:264-70.

20. Roberston SE et al. Rubella and congenital rubella syndrome: global update. Revista Panamericana de salud publica, 2003, 14(5):306-15.

21. Davidkin I et al. Duration of rubella immunity induced by two-dose measles, mumps and rubella (MMR) vaccination. A 15-year follow-up in Finland. Vaccine, 2000, 18(27):3106-12.

22. Wysokiñska $T$ et al. The prevalence of anti-rubella antibodies in women of childbearing age in Poland. Vaccine, 2004, 22:1899-902.

23. Vynnycky E, Gay NJ, Cutts FT. The predicted impact of private sector MMR vaccination on the burden of congenital rubella syndrome. Vaccine, 2003, 21:2708-19.

المجلة الصحية لشرق المتوسط، منظمة الصحة العالمية، المجلد الخامس عشر، العدد ب، 9 .. 